\title{
Factors Affecting Cloud Computing Adoption in Higher Education in Bangladesh: A Case of University of Dhaka
}

\author{
Jakia Sultana, Md. Fahami Ahsan Mazmum, Nymatul Jannat Nipa \\ Department of MIS, Faculty of Business Studies, University of Dhaka, Dhaka, Bangladesh \\ Email address: \\ jakia@du.ac.bd (J. Sultana), fahami@du.ac.bd (Md. F. A. Mazmum),nipa@du.ac.bd (N. J. Nipa)
}

\section{To cite this article:}

Jakia Sultana, Md. Fahami Ahsan Mazmum, Nymatul Jannat Nipa. Factors Affecting Cloud Computing Adoption in Higher Education in Bangladesh: A Case of University of Dhaka. Applied and Computational Mathematics. Vol. 6, No. 3, 2017, pp. 129-136.

doi: $10.11648 /$ j.acm.20170603.11

Received: February 26, 2017; Accepted: April 5, 2017; Published: May 17, 2017

\begin{abstract}
In the arena of education, Cloud computing is more apparent technology to ensure availability and sharing of resources through virtualization. To acquire benefit from this technology boon, it is important for an educational institution to identify the important factors that contribute on cloud computing adoption. So, this study has been conducted to identify the factors that will affect cloud computing adoption in educational sector. University of Dhaka is chosen as a case for this paper. Both primary and secondary sources are used for data collection. Seventeen potential factors are taken into consideration, on which survey has been conducted focusing primary sources. After performing multiple regression, variance inflation factor and factor analysis on data of primary source, six factors are identified as core factors to cloud computing adoption, these areservice availability, cloud control ability, resource need, usefulness in education, lack of proper infrastructure, lack of training of staff. These findings can be used as a theoretical base and future development of technological adoption in higher education.
\end{abstract}

Keywords: Cloud Computing, Adoption, Higher Education, University of Dhaka, Bangladesh

\section{Introduction}

Cloud computing is a new concept which is sprouting in the industry of information technology and academia. It is a cloud based development where the use of computer technology is used for virtualizing resources and providing services over the Internet (K. Srinivasa \& Ratna, 2013). Cloud Computing promises various benefits in the higher educational landscape by understanding different dynamics and expertise in diverse domain (MD. Anwar, Xiaodi, \& Jianming, 2012). Universities around the world are facing complexity in delivering ICT proficiency, needed to facilitate teaching, learning, research, and development activity in an typical university for not to adopting cloud computing (Safiya, Mueen, Amad, Raed, \& Asadullah, 2014). Many higher educational institutions are facing problems of lack of resources, which increase the importance of resource sharing. Where there is an issue of resource sharing, there the ideal solution is cloud computing (Muhammad, Fahad, Tasleem, \& Muhammad, 2012). If cloud computing can implement in higher educational sector, the problem of lack of resource will be solved and educational sector will boost up with the blessing of technological advantage. But like other developing countries, Bangladesh is lagging behind as the cloud computing cannot be adopted properly by the educational institution. If the determinants of cloud computing adoption can be identified, the educational sector of Bangladesh will also boost up with the blessings of cloud computing. That's why University of Dhaka is chosen as a sample to predict the factors behind the cloud computing adoption for other universities. The research question of this paper is "What are the factors that will affect the adoption of cloud computing in University of Dhaka of Bangladesh. The objectives of this study are: to identify the factors that affect the adoption of cloud computing in educational institution, to identify the most influential and less influential factors, to identify which users within University of Dhaka have exercised the most pressure to move towards the cloud computing. This paper is composed of five sections. Section one of this paper presents an introduction to this study. Literature review has been provided in second section. Third section of this study discusses the methodology. Data analysis and discussion is illustrated in fourth section. At last, fifth section offers the conclusion of this paper. 


\section{Literature Review}

Cloud computing is like "a new aurora" for educational sector as it enable students, researchers, lecturers, and administrative staff at colleges and universities to access services which is provided by new computing system (sultan, 2010). One study examining the determinants of cloud computing adoption by college and university, found that factors like complexity, institutional size, technological readiness are able to differenciate between the adopters and non- adopters of cloud computing (William \& Xue, 2015). Resources, issues, risks and ultimately best practices and standards will change the expectation and adoption of cloud computing in the future. In improving IT application and Infrastructure at educational institution, cloud computing can be used as considerable potential tool (K. Srinivasa \& Ratna, 2013). Cloud Computing can play a vital role in improving the quality of education by providing the educational content available to the student, teachers and the research scholar at the remote place. Cloud computing can solve the problem, "Equal Quality education for all" (BV Pranay, Sumitha, \& N. Uma, 2013). According to (George, Nikos, \& Lukas, 2013), data security, IT governance, service availability and dependence on service provider are the factors which work as a barrier to the adoption of the cloud computing of Czech Republic. Successful adoption of cloud computing depends of the realization of cloud computing environment (MD. Anwar, Xiaodi, \& Jianming, 2012). A study by (Hasan, 2013) found that Bangladesh lacks in financial resources, poor infrastructure and does not has proper approach toward the use of internet which affect the wide and deep adoption of the cloud computing. Top management support, Support and integration with university Services, Skills of IT human resources, Security effectiveness and Cost reduction are the main five dimensions for the adoption of Cloud Computing (Mansour, 2015). Infrastructure and the avaibale resources are important in implementing cloud computing archetecture (Shahid, Golam, Shaiful, Md. Zakir, \& Fariha, 2010). For delivering quality IT services to students, staff, and the educational community at reduced cost Cloud Computing can be an alternative way. But the primary factors or challenges in adoption of cloud computing may consider as minimum barrier in the educational sector (Safiya, Mueen, Amad, Raed, \& Asadullah, 2014). In a study by (AlAlaa \& Ibrahim, 2015) Relative advantage, complexity and data concern were identified as a factors that affect adoption of cloud computing in higher education institutions. A study by (Mohmed, Majzoob, \& Osama, 2016) consider the challenge of cloud computing are privacy and security issues. Security, Interoperability, Control, Performance, and reliability are the barriers of cloud computing adoption (Cisco, 2010). cloud computing has turn to a necessity for many higher learning institutions because it allows computing resources according user need, reducing management cost, resources cost, energy consumption and improving user scalabilities (L. Pushparani, Masih, Sanasam, \& L. Sashikumar, 2014). Main barriers of Cloud computing adoption are data security and privacy, dependence on service provider, service availability and high cost (GEORGE \& NIKOS, 2013). Support and Integration of Institution services with Cloud Computing and Top management support for the adoption of Cloud Computing are the main factors from many factors of cloud computing adoption (Nupur \& Sanjeev, 2014). For removing complexity of lack resources and knowledge to manage information technology for education, research, and development activities, educational institution should focus on the adoption of cloud computing (Mboungou, 2015). Security, lack of budget, lack of proper training, brainstorming of IT staff are the factors that afect adoption of cloud computing (Muhammad, Fahad, Tasleem, \& Muhammad, 2012). Factors that affect cloud computing adoption are relative advantage, compatibility, complexity, organizational readiness, top management commitment, and training and education, which is determined using perceived ease of use (PEOU) and perceived usefulness (PU) as mediating variables (Hemlata, Gangwar, \& R. Ramaswamy, 2015). (Anwar \& MD. Hossain, 2013) conduct a study on "M-learning Architecture for Cloud-based Higher Education System of Bangladesh" which conclude that security, privacy, and interoperability are some of the challenge which affects cloud based the M-leaning environment of the organization. According to (Muhammad Ataur \& Masudur, 2014) Infrastructure is a major issue for adopting cloud computing as because of their improved infrastructure the more developed countries (MDCs) are adopting the benefits of cloud computing quickly. (Mahmoud, Kevin, \& Alexeis, 2015) conduct a study on "The Impacts of Cloud Computing Adoption at Higher Education Institutions: A SWOT Analysis" Which conclude that legal and policy constraints should consider seriously at the time of migrating to cloud. A study by (Oyeleye, Fagbola, \& Daramola, 2014) reveals that the adopting of cloud computing has an important impact on cost effectiveness, enhanced availability, low environmental impact, reduced IT complexities, mobility, scalability, increased operability and reduced investment in physical asset. Using Partial Least Square a study is conducted on "Cloud Computing Adoption by Higher Education Institutions in Saudi Arabia" and found that the factors that influence the adoption by higher education institutions were Relative Advantage, Data Privacy and Complexity are the most significant factors (AlAlaa\& Ibrahim, 2014). Lack of adequate infrastructure in Nigeria is concluded as a major determinants of cloud computing adoption by the study on "Factor Analysis of the Adoption of Cloud Computing in Nigeria" (Awosan, 2014).

\section{Variable Identification}

Different authors wrote different kinds of papers to find out the factors of cloud computing adoption in education sectors of various countries. By analyzing the outcomes and the literature reviews of various papers on cloud computing, some variables have been identified and by analyzing the higher educational context of universities of Bangladesh some other variables have been identified. There are total seventeen (17) variables that are identified as a predictor of 
cloud computing adoption for this paper. These variables are, technological infrastructure, resource need, risk of privacy, data security, service availability, dependence on service provider, skills of IT personnel, integration with organizational service, lack of proper infrastructure, cloud control ability, cost of access, lack of training of staff, knowledge of cloud computing threats, usefulness in education, regulatory policy, transparency of cloud provider operations and organizational size.

\section{Research Methodology}

This study has been conducted for unveiling the information on factors that influence the adoption of cloud computing in educational institution. Considering the pervious study, first data are collected from secondary sources, then seventeen variables are identified, on which a questionnaire is developed later. The questionnaire is enriched with some short questions, multiple choice questions and some 5 point likert scale questions to procure information on various necessary criteria. A survey using this questionnaire has been conducted to obtain the primary data. Convenience sampling techniques are taken as sampling technique for this research. Convenience sampling is a nonprobability sampling where subjects are selected because of their convenient accessibility proximity to the researcher. Entire respondents of the survey are grouped into six categories: IT staff, administrative staff, librarians, post graduates, graduates and undergraduates. Both physical questionnaire and Google form based questionnaire are used to gather survey data. The population of the study is all stakeholders of University of the Dhaka and 294 samples are picked for analysis. Secondary data sources of this paper are various websites, journals, articles, books etc.

The nature of this research is descriptive. As in this study quantitative method is used, so different statistical analyses have been applied on data that are collected through primary sources. To test the multicolinearity, variance inflation factor (VIF) test has been conducted which ensure that the considered variables are the core variables which can be used for predicting depended variable. To make sure the reliability of survey instrument, reliability testis also conducted. Multiple regression and factor analysis are conducted to know the how much independent variable fit to predict dependent variable and for factor reduction respectively. For all this analysis purpose, Statistical Package for Social Science (SPSS) 20.0 and Microsoft Excel 2010 have been used.

\section{Respondent Profile}

In this paper, data are collected from different types of respondents of University of Dhaka. Both male and female ages between 18-50 years are respondents of this survey. Researchers of this study has taken responses from respondents of different educational backgrounds like- $\mathrm{PhD}$, post graduation, graduation, HSC, SSC and different professions teacher, IT officer, administrative officer, librarian, postgraduate student, undergraduate student and other professions of University of Dhaka. Respondents from different departments and libraries of different faculties likeFaculty of Arts, Faculty of Business Studies, Faculty of Biological Science, Faculty of Engineering and Technology, Faculty of Education, Faculty of Fine Arts, Faculty of Law, Faculty of Medicine, Faculty of Postgraduates Medical Sciences \& Research, Faculty of Pharmacy, Faculty of Science, Faculty of Social Sciences, Faculty of Earth and Environmental Sciences as well as different institutes likeInstitute of Education and Research, Institute of Statistical Research and Training, Institute of Business Administration, Institute of Nutrition and Food Science, Institute of Social Welfare and Research, Institute of Modern Languages, Institute of Health Economics, Institute of Information Technology, Institute of Renewable Energy, Institute of Disaster Management and Vulnerability Studies, Institute of Leather Engineering \& Technology are ensured. Reponses from respondents' like- librarian, administrative officer of Central library have been ensured. IT officer, administrative officer and other officers of Registrar building are also included as respondents of this questionnaire survey. In the way, responses of all stakeholders of University of Dhaka have been covered.

\section{Data Analysis and Discussion}

Seventeen Variables that are taken into consideration for analysis are- technological infrastructure, resource need, risk of privacy, data security, service availability, dependence on service provider, skills of IT personnel, integration with organizational service, lack of proper infrastructure, cloud control ability, cost of access, lack of training of staff, knowledge of cloud computing threats, usefulness in education, regulatory policy, transparency of cloud provider operations and organizational size. However, organizational size and transparency of cloud provider are not considered in factor analysis and multiple regressions.

Variance Inflation Factor

Table 1. Variance Inflation Factor.

\begin{tabular}{|c|c|c|}
\hline \multirow{2}{*}{ Model } & \multicolumn{2}{|c|}{ Collinearity Statistics } \\
\hline & Tolerance & VIF \\
\hline \multicolumn{3}{|l|}{ (Constant) } \\
\hline Technological infrastructure & .780 & 1.282 \\
\hline Resource need & .705 & 1.418 \\
\hline Risk of privacy & .669 & 1.494 \\
\hline Data security & .496 & 2.017 \\
\hline Service availability & .592 & 1.690 \\
\hline Dependence on service provider & .776 & 1.288 \\
\hline Skill of IT personnel & .427 & 2.344 \\
\hline Integration with organizational service & .559 & 1.789 \\
\hline Lack of proper infrastructure & .687 & 1.456 \\
\hline Cloud control ability & .585 & 1.710 \\
\hline Cost of access & .798 & 1.254 \\
\hline Lack of training of staff & .660 & 1.516 \\
\hline Knowledge of cloud computing threats & .553 & 1.808 \\
\hline Usefulness in education & .701 & 1.427 \\
\hline Regulatory policy & .642 & 1.558 \\
\hline Organizational size & .834 & 1.199 \\
\hline Transparency of cloud provider & .843 & 1.186 \\
\hline
\end{tabular}


In this analysis seventeen variables are taken into consideration. The collinearity statistics shows that the VIF value of the variable are less than 5 and the tolerance values are greater than 0.2 , which implies that the independent variables does not process multiple collinearity. There is no correlation between independent variables. So these variables are appropriate and can be used for analysis.

Multiple Regressions

Table 2. Multiple Regressions.

\begin{tabular}{|c|c|c|c|c|c|c|c|c|c|c|}
\hline \multicolumn{11}{|c|}{ Model Summary $^{\mathbf{b}}$} \\
\hline \multirow[b]{2}{*}{ Model } & \multirow[b]{2}{*}{$\mathbf{R}$} & \multirow[b]{2}{*}{ R Square } & \multirow[b]{2}{*}{$\begin{array}{l}\text { Adjusted } \\
\text { R Square }\end{array}$} & \multirow[b]{2}{*}{$\begin{array}{l}\text { Std. Error of } \\
\text { the Estimate }\end{array}$} & \multicolumn{5}{|c|}{ Change Statistics } & \multirow[b]{2}{*}{ Durbin-Watson } \\
\hline & & & & & $\begin{array}{l}\text { R Square } \\
\text { Change }\end{array}$ & F Change & df1 & df2 & Sig. F Change & \\
\hline 1 & $.906^{\mathrm{a}}$ & .821 & .811 & .28980 & .821 & 84.714 & 15 & 277 & .000 & 1.860 \\
\hline \multicolumn{11}{|c|}{$\begin{array}{l}\text { a. Predictors: (Constant), regulatory policy, cost of access, technological infrastructure, dependence on service provider, lack of training of staff, service } \\
\text { availability, resource need, usefulness in education, risk of privacy, lack of proper infrastructure, cloud control ability, knowledge of cloud computing } \\
\text { threats, integration with organizational service, data security, skill of IT personnel } \\
\text { b. Dependent Variable: overall adoption }\end{array}$} \\
\hline
\end{tabular}

Table 3. ANOVA.

\begin{tabular}{|c|c|c|c|c|c|c|}
\hline \multicolumn{7}{|c|}{ ANOVA $^{a}$} \\
\hline \multicolumn{2}{|c|}{ Model } & $\begin{array}{l}\text { Sum of } \\
\text { Squares }\end{array}$ & Df & $\begin{array}{l}\text { Mean } \\
\text { Square }\end{array}$ & $\mathbf{F}$ & Sig. \\
\hline \multirow{3}{*}{1} & Regression & 106.722 & 15 & 7.115 & 84.714 & $.000^{b}$ \\
\hline & Residual & 23.264 & 277 & .084 & & \\
\hline & Total & 129.986 & 292 & & & \\
\hline
\end{tabular}

a. Dependent Variable: overall adoption

b. Predictors: (Constant), regulatory policy, cost of access, technological infrastructure, dependence on service provider, lack of training of staff, service availability, resource need, usefulness in education, risk of privacy, lack of proper infrastructure, cloud control ability, knowledge of cloud computing threats, integration with organizational service, data security, skill of IT personnel

After performing reliability test, as an outcome two variables are shown unreliable. So these variables are removed and multiple regressions have been conducted on remaining fifteen variables. The table shows that the value of correlation coefficient $\mathrm{R}=.906$, which implies that there exists a high degree of positive relationship between dependent variable (overall adoption) and independent variable(transparency fcloud provider, knowledge of cloud computing threats, dependence on service provider, technological infrastructure, cost of access, organizational size, usefulness in education, risk of privacy, lack of proper infrastructure, resource need, integration with organizational service, service availability, regulatory policy, lack of training of staff, cloud control ability, data security, skill of IT personnel). Here R2 $=.821$ which implies that $82.1 \%$ of the total variation of overall adoption of cloud computing can be explained by regression model (by the variation in factors affecting cloud computing adoption). The fitness of the model is $81.1 \%$.

The total variance has N-1 degrees of freedom. The regression degrees of freedom correspond to the number of coefficients estimated minus 1 . Including the intercept, there are 18 coefficients, so the model has $16-1=15$ degrees of freedom. The Error degree of freedom is the DF total minus the DF model, $292-15=277$. The F-statistic, the p-value associated with it. The F-statistic is the Mean Square (Regression) divided by the Mean Square (Residual): $7.115 / .084=84.714$.

Table 4. Coefficients.

\begin{tabular}{|c|c|c|c|c|c|c|}
\hline \multicolumn{7}{|c|}{ Coefficients $^{\mathrm{a}}$} \\
\hline \multirow{2}{*}{\multicolumn{2}{|c|}{ Model }} & \multicolumn{2}{|c|}{ Unstandardized Coefficients } & \multirow{2}{*}{$\begin{array}{l}\text { Standardized Coefficients } \\
\text { Beta }\end{array}$} & \multirow{2}{*}{$\mathbf{t}$} & \multirow{2}{*}{ Sig. } \\
\hline & & B & Std. Error & & & \\
\hline \multirow{16}{*}{1} & (Constant) & -.218 & .132 & & -1.651 & .100 \\
\hline & technological infrastructure & .040 & .021 & .055 & 1.895 & .059 \\
\hline & Resource need & .062 & .022 & .084 & 2.774 & .006 \\
\hline & Risk of privacy & .017 & .022 & .025 & .789 & .431 \\
\hline & Data security & .021 & .028 & .028 & .766 & .444 \\
\hline & Service availability & .106 & .025 & .141 & 4.253 & .000 \\
\hline & Dependence on service provider & .059 & .019 & .089 & 3.093 & .002 \\
\hline & Skill of IT personnel & .023 & .025 & .035 & .905 & .366 \\
\hline & Integration with organizational service & .085 & .025 & 117 & 3.444 & .001 \\
\hline & Lack of proper infrastructure & .086 & .019 & .140 & 4.560 & .000 \\
\hline & Cloud control ability & .128 & .022 & .191 & 5.746 & .000 \\
\hline & Cost of access & .083 & .018 & .128 & 4.513 & .000 \\
\hline & Lack of training of staff & .039 & .018 & .069 & 2.200 & .029 \\
\hline & Knowledge of cloud computing threats & .063 & .022 & .100 & 2.926 & .004 \\
\hline & Usefulness in education & .138 & .023 & .185 & 6.087 & .000 \\
\hline & Regulatory policy & .102 & .021 & .151 & 4.744 & .000 \\
\hline
\end{tabular}

a. Dependent Variable: overall adoption 
$\mathrm{B}$, are the values for the regression equation for predicting the dependent variable from the independent variable. The regression equation is presented below-

$\mathrm{Y}$ (Overall satisfaction) $=\mathrm{b} 0+\mathrm{b} 1 *$ technological infrastructure $+b 2 *$ resource need $+b 3 *$ risk of privacy $+\mathrm{b} 4 *$ data security $+\mathrm{b} 5 *$ service availability + $\mathrm{b} 6 *$ dependenceonserviceprovider $+\mathrm{b} 7 *$ skillofITpersonnel $+\mathrm{b} 8$ $*$ integrationwith organizational service $+\mathrm{b} 9 *$ lack of proper infrastructure

$+\mathrm{b} 10 *$ cloudcontrolability $+\mathrm{b} 11 *$ costofaccess $+\mathrm{b} 12 *$ lackoftrain ingofstaff

$+\mathrm{b} 13 *$ knowledgeofcloudcomputingthreats $+\mathrm{b} 14 *$ usefulness in education $+\mathrm{b} 15 *$ regulatory policy $+\mathrm{b} 16 *$ organizational size $+\mathrm{b} 17 *$ transparency of cloud provider $+\mathrm{E}$

The column of estimates provides the values for $b 0, b 1$, b2, b3, b4, b5, b6, b7, b8, b9, b10, b11, b12, b13, b14, b15, b16 and b17 for this equation. The t-statistics and their associated 2-tailed p-values used in testing whether a given coefficient is significantly different from zero. Using an alpha of 0.05 , the significant value can be calculated, mainly the variable which $\mathrm{p}$ value is smaller than 0.05 and $\mathrm{T}$ value is

greater than 1.96 are considered as significant one. So the significant variables are- resource need, service availability, dependence on service provider, integration with organizational service, lack of proper infrastructure, cloud control ability, cost of access, lack of training of staff, knowledge of cloud computing threats, usefulness in education, regulatory policy

Reliability analysis: (Initial table)

Table 5. Reliability analysis: (Initial).

\begin{tabular}{lll}
\hline \multicolumn{2}{l}{ Reliability Statistics } & \\
\hline $\begin{array}{l}\text { Cronbach's } \\
\text { Alpha }\end{array}$ & $\begin{array}{l}\text { Cronbach's Alpha Based on } \\
\text { Standardized Items }\end{array}$ & N of Items \\
\hline .865 & .873 & 18 \\
\hline
\end{tabular}

Reliability analysis: (Improved table)

Table 6. Reliability analysis: (Improved).

\begin{tabular}{lll}
\hline Reliability Statistics & & \\
\hline Cronbach's Alpha & $\begin{array}{l}\text { Cronbach's Alpha Based on } \\
\text { Standardized Items }\end{array}$ & N of Items \\
\hline .880 & .886 & 16 \\
\hline
\end{tabular}

Table 7. Item-Total Statistics.

\begin{tabular}{|c|c|c|c|c|c|}
\hline \multicolumn{6}{|l|}{ Item-Total Statistics } \\
\hline & $\begin{array}{l}\text { Scale Mean if } \\
\text { Item Deleted }\end{array}$ & $\begin{array}{l}\text { Scale Variance if } \\
\text { Item Deleted }\end{array}$ & $\begin{array}{l}\text { Corrected Item- } \\
\text { Total Correlation }\end{array}$ & $\begin{array}{l}\text { Squared Multiple } \\
\text { Correlation }\end{array}$ & $\begin{array}{l}\text { Cronbach's Alpha } \\
\text { if Item Deleted }\end{array}$ \\
\hline Technological infrastructure & 60.1843 & 78.144 & .376 & .230 & .879 \\
\hline Resource need & 60.2082 & 76.980 & .458 & .314 & .875 \\
\hline Risk of privacy & 60.3072 & 75.577 & .529 & .332 & .873 \\
\hline Data security & 60.0648 & 74.862 & .626 & .505 & .869 \\
\hline Service availability & 60.2526 & 75.792 & .550 & .445 & .872 \\
\hline Dependence on service provider & 60.8601 & 77.347 & .374 & .250 & .879 \\
\hline Skill of IT personnel & 60.1980 & 72.468 & .667 & .575 & .866 \\
\hline Integration with organizational service & 60.4403 & 74.610 & 609 & .464 & .869 \\
\hline Lack of proper infrastructure & 60.8976 & 75.983 & .420 & .361 & .878 \\
\hline Cloud control ability & 60.3584 & 73.498 & .619 & .477 & .869 \\
\hline Cost of access & 60.6519 & 76.817 & .400 & .257 & .878 \\
\hline Lack of training of staff & 60.6075 & 73.657 & .500 & .352 & .875 \\
\hline Usefulness in education & 60.1263 & 77.398 & .438 & .382 & .876 \\
\hline Regulatory policy & 60.5461 & 74.920 & .538 & .406 & .872 \\
\hline Overall adoption & 60.4266 & 74.348 & .893 & .821 & .863 \\
\hline
\end{tabular}

To ensure that this paper's measurement is error free, it is necessary to test its reliability. Cronbach's coefficient alpha, $(\alpha)$ is used as the common measure of scale reliability. It also measures internal consistency of the items. Its value ranges from 0 to 1 and higher values indicate greater reliability. From initial table of reliability analysis, the alpha coefficient for the 18 items is. 865 , suggesting that the items have relatively high internal consistency. As result of initial reliability analysis, two variables' values (organizational size and transparency of cloud provider) are found greater than the current alpha of the whole scale: .865(Item-Total Statistics table of initial reliability analysis has been skipped for better view). This means that it is necessary to drop these two items. So it is needed to run reliability analysis on remaining items again. As a result, the value of Cronbach's coefficient alpha is increased from 0.865 to
0.880. From the item-total statistics of improved reliability analysis; it is clear that that none of the values is greater than the current alpha of the whole scale:.880. Then this means that it is not necessary to drop any items in this turn. Therefore, the survey questionnaire can be a reliable tool to measure all construct consistency.

Factor Analysis

To test appropriateness of factor model, it is needed to check measure of sampling adequacy. In addition to this it is also needed to test whether variables are correlated or not. Kaiser-Meyer-Olkin Measure of Sampling Adequacy index and Bartlett's Test of Sphericity are used for sampling adequacy and correlation test respectively. The test result is shown below: 
Table 8. KMO and Bartlett's Test.

\begin{tabular}{lll}
\hline KMO and Bartlett's Test & \\
\hline \multicolumn{3}{l}{ Kaiser-Meyer-Olkin Measure of Sampling Adequacy. } \\
& Approx. Chi-Square & .880 \\
\multirow{3}{*}{ Bartlett's Test of Sphericity } & Df & 1322.493 \\
& Sig. & .000 \\
\hline
\end{tabular}

Kaiser-Meyer-Olkin Measure of Sampling Adequacy index is. 880 indicates that the factor analysis is appropriate for the surveyed data set. High values (between 0.5 and 1.0) indicate factor analysis is appropriate and values below 0.5 imply that factor analysis may not be appropriate. Bartlett's Test of Sphericity is a statistic used to examine the hypothesis that variables are uncorrelated i.e. the population correlation matrix is an identity matrix. A large value of the test statistic will favor the rejection of null hypothesis. The result shows that Bartlett's Test of Sphericity Chi-Square statistics is 1322.493 with 105 degrees of freedom at $5 \%$ level of significance, which would mean that fifteen variables are correlated and therefore it can be concluded from the KMO and Bartlett's Test of Sphericity that the factor analysis is appropriate for the surveyed data set.

Table 9. Communalities.

\begin{tabular}{lll}
\hline Communalities & & \\
\hline & Initial & Extraction \\
\hline Technological infrastructure & 1.000 & .380 \\
Resource need & 1.000 & .505 \\
Risk of privacy & 1.000 & .446 \\
\hline
\end{tabular}

\begin{tabular}{lll}
\hline Communalities & & \\
\hline & Initial & Extraction \\
\hline Data security & 1.000 & .593 \\
Service availability & 1.000 & .624 \\
Dependence on service provider & 1.000 & .431 \\
Skills of IT personnel & 1.000 & .658 \\
Integration with organizational service & 1.000 & .508 \\
Lack of proper infrastructure & 1.000 & .657 \\
Cloud control ability & 1.000 & .530 \\
Cost of access & 1.000 & .423 \\
Lack of training of staff & 1.000 & .541 \\
Knowledge of cloud computing threats & 1.000 & .483 \\
Usefulness in education & 1.000 & .540 \\
Regulatory policy & 1.000 & .471 \\
\hline
\end{tabular}

Initial communalities are estimates of the variance in each variable accounted for by all components or factors. For principal components extraction, this is always equal to 1.0 for correlation analyses. Extraction communalities are estimates of the variance in each variable accounted for by the components. The communalities in above table are all high, which indicates that the extracted components represent the variables well. If any communality is very low in a principal components extraction, it is needed to extract another component. Skill of IT personnel has high communalities (.658). Others are lack of proper infrastructure (.657), data security (.593), lack of training of staff (.541), usefulness in education (.540), cloud control ability (.530), integration with organizational service (.508), resource need (.505).

Table 10. Total Variance Explained.

\begin{tabular}{|c|c|c|c|c|c|c|c|c|c|}
\hline \multicolumn{10}{|c|}{ Total Variance Explained } \\
\hline \multirow{2}{*}{ Component } & \multicolumn{3}{|c|}{ Initial Eigenvalues } & \multicolumn{3}{|c|}{$\begin{array}{l}\text { Extraction Sums of } \\
\text { Squared Loadings }\end{array}$} & \multicolumn{3}{|c|}{$\begin{array}{l}\text { Rotation Sums } \\
\text { of Squared Loadings }\end{array}$} \\
\hline & Total & $\begin{array}{l}\% \text { of } \\
\text { Variance }\end{array}$ & Cumulative $\%$ & Total & $\begin{array}{l}\% \text { of } \\
\text { Variance }\end{array}$ & Cumulative \% & Total & $\begin{array}{l}\% \text { of } \\
\text { Variance }\end{array}$ & Cumulative \% \\
\hline 1 & 5.322 & 35.478 & 35.478 & 5.322 & 35.478 & 35.478 & 3.162 & 21.082 & 21.082 \\
\hline 2 & 1.348 & 8.989 & 44.467 & 1.348 & 8.989 & 44.467 & 2.474 & 16.492 & 37.575 \\
\hline 3 & 1.119 & 7.462 & 51.928 & 1.119 & 7.462 & 51.928 & 2.153 & 14.354 & 51.928 \\
\hline 4 & .879 & 5.857 & 57.785 & & & & & & \\
\hline 5 & .845 & 5.634 & 63.420 & & & & & & \\
\hline 6 & .751 & 5.009 & 68.429 & & & & & & \\
\hline 7 & .736 & 4.903 & 73.332 & & & & & & \\
\hline 8 & .676 & 4.503 & 77.835 & & & & & & \\
\hline 9 & .608 & 4.053 & 81.889 & & & & & & \\
\hline 10 & .563 & 3.754 & 85.643 & & & & & & \\
\hline 11 & .536 & 3.573 & 89.216 & & & & & & \\
\hline 12 & .508 & 3.387 & 92.603 & & & & & & \\
\hline 13 & .453 & 3.020 & 95.623 & & & & & & \\
\hline 14 & .384 & 2.560 & 98.183 & & & & & & \\
\hline 15 & .273 & 1.817 & 100.000 & & & & & & \\
\hline
\end{tabular}

From the above table, only 3 factors have been extracted, as cumulative percentage is greater than $51 \%$ at this point and eigen value is greater than 1.0 (it is recommended that factors with eigen values greater than 1.0 should be retained) that indicates the adequacy of the analysis using derived. The complexity of the data set can be reduced by using these components, with only a $48.072 \%$ loss of information.
Table 11. Rotated Component Matrix.

\begin{tabular}{llll}
\hline Rotated Component Matrix $^{\mathbf{a}}$ & \multicolumn{3}{l}{ Component } \\
\cline { 2 - 4 } & $\mathbf{1}$ & $\mathbf{2}$ & $\mathbf{3}$ \\
\hline Technological infrastructure & .229 & .570 & -.047 \\
Resource need & .193 & .682 & .053 \\
Risk of privacy & .612 & .190 & .189 \\
Data security & .695 & .295 & .151 \\
Service availability & .772 & .163 & .037 \\
Dependence on service provider & .317 & -.089 & .568 \\
\hline
\end{tabular}




\begin{tabular}{llll}
\hline Rotated Component Matrix $^{\mathbf{a}}$ & \multicolumn{3}{l}{ Component } \\
\cline { 2 - 4 } & $\mathbf{1}$ & $\mathbf{2}$ & $\mathbf{3}$ \\
\hline Skills of IT personnel & .725 & .328 & .160 \\
Integration with organizational service & .551 & .216 & .398 \\
Lack of proper infrastructure & .012 & .162 & .794 \\
Cloud control ability & .635 & .252 & .250 \\
Cost of access & .334 & -.052 & .556 \\
Lack of training of staff & .094 & .392 & .615 \\
Knowledge of cloud computing threats & .318 & .547 & .286 \\
Usefulness in education & .157 & .717 & .022 \\
Regulatory policy & .199 & .559 & .345 \\
\hline
\end{tabular}

The rotated component matrix helps to determine what the components represent. The first component has high correlation with risk of privacy, data security, service availability, skill of IT personnel, cloud control ability. The second component has high correlation with resource need, usefulness in education. Third component has high correlation with lack of proper infrastructure, lack of training of staff.

\section{Conclusion}

Cloud computing is a new concept for Bangladesh. Its adoption in different sectors requires a careful attention. So to adopt this technology in education institution as a specific sector, it is necessary to understand the factors that will affect its adoption in this sector. The goal of this study is to identify the factors that will influence cloud computing adoption in University of Dhaka of Bangladesh. In this study some significant factors has been derived from data collection and data analysis on different parties of this university. Lack of proper infrastructure, service availability and usefulness in education are found most important. Other factors are resource need, cloud control ability and lack of training of staff. Educational institution can focus on these factors to increase the use of cloud computing technology to provide learning to student. In future, researcher can work further on this topic by extending the scope of the study from University of Dhaka to all universities and all institutions in Bangladesh.

\section{References}

[1] AlAlaa, N. T., \& Ibrahim, M. A.-J. (2015). Cloud computing adoption by higher education institutions in Saudi Arabia: an exploratory study. Springer Science Business Media New York.

[2] AlAlaa, T., \& Ibrahim, A.-J. (2014). Cloud Computing Adoption by Higher Education Institutions in Saudi ArabiaAnalysis Based on TOE. SSRN.

[3] Anwar, \& MD. Hossain, M. X. (2013). M-learning Architecture for Cloud-based Higher Education System of Bangladesh. www.mc-journal.org.

[4] Awosan, R. (2014). Factor Analysis of the Adoption of Cloud Computing In Nigeria. African Journal of Computing \& ICT, Vol 7. No. 1 .

[5] BV Pranay, k., Sumitha, k., \& N. Uma, R. (2013).
EFFECTIVE WAYS CLOUD COMPUTING CAN CONTRIBUTE TO EDUCATION SUCCESS. Advanced Computing: An International Journal (ACIJ), Vol.4, No.4.

[6] Cisco. (2010). Cloud Computing in Higher Education: A Guide to Evaluation and Adoption. http://www.sei.cmu.edu/sos/research/cloudcomputing/cloudba rriers.cfm.

[7] GEORGE, F., \& NIKOS, M. (2013). Cloud Computing Adoption: A comparative study. Latest Trends in Information Technology.

[8] George, F., Nikos, M., \& Lukas, B. (2013). Cloud Computing Adoption: A comparative Study. Cloud Computing Research Group.

[9] Hasan, M. A. (2013). Goodness of Cloud Computing: does Bangladesh ready for it. Global Disclosure of Economics and Business, Volume 2, No 2, Asian Business Consortium.

[10] Hemlata, Gangwar, H. D., \& R. Ramaswamy. (2015). Understanding determinants of Understanding determinants of an integrated TAM-TOE model. Journal of Enterprise Information Management.

[11] K. Srinivasa, R., \& Ratna, K. C. (2013). Adoption of Cloud Computing In Education and Learning. International Journal of Advanced Research in Computer and Communication Engineering, Vol. 2, Issue 10.

[12] L. Pushparani, D., Masih, S., Sanasam, B., \& L. Sashikumar, S. (2014). Cloud Technology in Higher Teacher Education Institutions: A Solution to ICT Infraucture adoption problem. International Journal of Advanced Studies in Computer Science and Engineering, IJASCSE Volume 3, Issue 4.

[13] Mahmoud, O., Kevin, W., \& Alexeis, G.-P. (2015). The Impacts of Cloud Computing Adoption at Higher Education Institutions: A SWOT Analysis. International Journal of Computer Applications (0975 - 8887), Volume 127 - No.4.

[14] Mansour, A. J. (2015). The Adoption of Cloud Computing Technology in Higher Education Institutions: Concerns and Challenges (Case Study on Islamic University of Gaza IUG)'. Not published yet.

[15] Mboungou, M. S. (2015). Higher Education and the Adoption of Cloud Computing Technology in Africa. International Journal on Communications (IJC) Volume 4.

[16] MD. Anwar, H. M., Xiaodi, H., \& Jianming, Y. (2012). Cloud Computing for Higher Education: A Roadmap. https://www.researchgate.net/publication/234801620. Research Gate.

[17] Mohmed, S. A., Majzoob, K., \& Osama, E. S. (2016). Cloud Computing Adoption in the Higher Education (Sudan as a model): A SWOT Analysis. American Journal of Information Systems, Science and Education Publishing, Vol. 4, No. 1, 7-10.

[18] Muhammad Ataur, R. M., \& Masudur, R. (2014). Improvments of Cloud Computing: Scenario of LDCs and MDCs. International Journal of Scientific \& Engineering Research, Volume 5, Issue 2.

[19] Muhammad, H. A., Fahad, J., Tasleem, M., \& Muhammad, S. F. (2012). Cloud Computing: A General User's Perceptions and Security Issues at Universities of Faisalabad, Pakistan. IJCSI International Journal of Computer Science Issues, Vol. 9, Issue 5, No 2. 
[20] Nupur, G., \& Sanjeev, T. (2014). THE FACTORS AFFECTING ADOPTION of CLOUD COMPUTING TECHNOLOGY in EDUCATION INSTITUTIONS. International Journal of Advanced Research in Computer and Communication Engineering, Vol. 3, Issue 6.

[21] Oyeleye, C. A., Fagbola, T. M., \& Daramola, C. Y. (2014). The Impact and Challenges of Cloud Computing Adoption on Public Universities in Southwestern Nigeria. IJACSA) International Journal of Advanced Computer Science and Applications, Vol. 5, No. 8.

[22] Safiya, O., Mueen, U., Amad, A., Raed, A., \& Asadullah, S. (2014). Cloud Computing Adoption Model for Universities to Increase ICT Proficiency. SAGE Open.

[23] Shahid, A. N., Golam, M., Shaiful, A. C., Md. Zakir, H., \& Fariha, T. J. (2010). A Proposed Architecture of Cloud Computing for Education System in Bangladesh and the Impact on Current Education System. IJCSNS International
Journal of Computer Science and Network Security, VOL.10 No.10.

[24] sultan, n. (2010). Cloud computing for education: A new dawn. International Journal of Information Management, 109-116.

[25] William, K., \& Xue, B. (2015). FACTORS AFFECTING CLOUD COMPUTING ADOPTION AMONG UNIVERSITIES AND COLLEGES IN THE UNITED STATES AND CANADA. Issues in Information Systems, Volume 16, Issue III, pp. 1-10.

[26] wikipedia. (2016, 05 18). wikipedia. Retrieved 05 19, 2016 , from wikipidia.com: https://en.wikipedia.org/wiki/Cloud_computing (Should be deleted). 